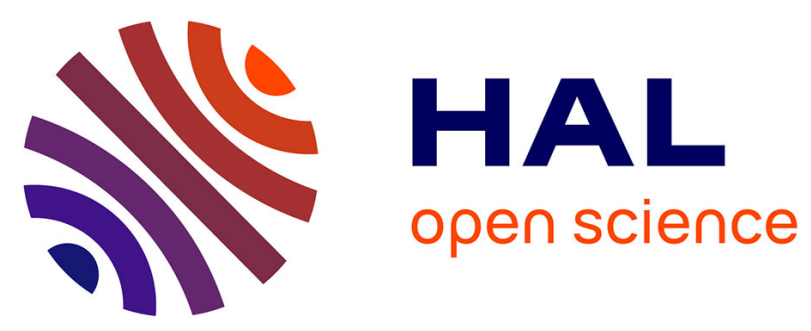

\title{
Polychromatic laser guide star using a single laser at 330 nm
}

\author{
J.P. Pique, Ioana C. Moldovan, Vincent Fesquet, Hugues Guillet de Chatellus, \\ Fabien Marc
}

\section{- To cite this version:}

J.P. Pique, Ioana C. Moldovan, Vincent Fesquet, Hugues Guillet de Chatellus, Fabien Marc. Polychromatic laser guide star using a single laser at $330 \mathrm{~nm}$. Proceedings of SPIE, the International Society for Optical Engineering, 2006, Advances in Adaptive Optics II. Edited by Ellerbroek, Brent L.; Bonaccini Calia, Domenico., 6272, pp.62723D. 10.1117/12.692350 . hal-01118420

\author{
HAL Id: hal-01118420 \\ https://hal.science/hal-01118420
}

Submitted on 3 Mar 2015

HAL is a multi-disciplinary open access archive for the deposit and dissemination of scientific research documents, whether they are published or not. The documents may come from teaching and research institutions in France or abroad, or from public or private research centers.
L'archive ouverte pluridisciplinaire HAL, est destinée au dépôt et à la diffusion de documents scientifiques de niveau recherche, publiés ou non, émanant des établissements d'enseignement et de recherche français ou étrangers, des laboratoires publics ou privés. 


\title{
Polychromatic Laser Guide Star using a single laser at $330 \mathrm{~nm}$
}

\author{
Jean-Paul Pique*, Ioana C. Moldovan, Vincent Fesquet, \\ Hugues Guillet de Chatellus and Fabien Marc \\ Laboratoire de Spectrométrie Physique, Université Joseph Fourier, UMR 5588 CNRS- Grenoble I, \\ B.P. 87, 38402 saint Martin d'Hères, FRANCE
}

\begin{abstract}
The differential atmospheric tip-tilt can be measured using a Polychromatic Laser Guide Star. A two photon excitation has been proposed. It consists in exciting the $4 \mathrm{D}_{5 / 2}$ level of mesospheric sodium atoms with two identical lasers operating at $589 \mathrm{~nm}$ and $569 \mathrm{~nm}$. With two modeless lasers of $2 \times 15 \mathrm{~W}$ at the mesosphere level, this scheme will produce a returned flux at $330 \mathrm{~nm}$ of about $4 \times 10^{4}$ photons $/ \mathrm{s} / \mathrm{m}^{2}$. Thanks to our modeless laser, we propose a new method which consists in exciting directly the $4 \mathrm{P}_{3 / 2}$ sodium level with one photon excitation, using a single laser operating at $330 \mathrm{~nm}$. This solution was previously rejected probably because of strong saturation problems using single longitudinal mode lasers. We show that $1 \mathrm{~W}$ modeless laser at $330 \mathrm{~nm}$ can produce the same returned flux at $330 \mathrm{~nm}$. This solution will save at least $400 \mathrm{k} €$ of equipment. Moreover, our new method is very promising in terms of simplicity but also in terms of flux because the returned flux above will probably be not sufficient for getting a good Strehl ratio. We propose very efficient solid state laser systems for the production of tens of watts at $330 \mathrm{~nm}$.
\end{abstract}

Keywords: Laser guide star, polychromatic laser guide star, sodium, laser-sodium interaction, atomic model, UV excitation, modeless laser, atmospheric tip-tilt, adaptive optics, solid state laser, UV laser.

\section{INTRODUCTION}

\subsection{Monochromatic Laser Guide Star}

To increase the sky coverage using adaptive optics (AO), large astronomical facilities implement monochromatic laser guide star (LGS) ${ }^{1,2,3,4,5}$. Three telescopes of 8-10 meters are now equipped with LGS. An important progress was achieved in 2004 on a 10 meter family telescope at Keck Observatory ${ }^{6}$ where AO works well thanks to a natural guide star for tip-tilt correction (TTNGS from «tip-tilt natural guide star ») and a $9.5^{\text {th }}$ magnitude LGS for higher order corrections. Under normal seeing conditions, the Keck LGS AO system produces K-band Strehl ratios between 30 and $40 \%$ using bright tip-tilt guide stars of $14^{\text {th }}$ magnitude. The Keck II LGS AO is becoming a prolific system from an astronomical point of view. Thirty LGS AO science nights have been allocated in the second half of 2005. The Keck II laser is a 12 watt $^{7}$ dye MOPA laser channel fabricated by Lawrence Livermore National Laboratory (LLNL) and delivered in $1998^{8}$. The laser beam is launched on the side of the primary mirror which gives asymmetric elongation spots on the wave front sensor. The Gemini North Laser Guide Star Program was launched back in early 1999 with the beginning of an active search for a suitable laser solid state laser developed by Coherent Technologies Inc. The 12 Watts Gemini North laser is a frequency mixing of two mode locked YAG lasers at $1.319 \mu \mathrm{m}$ and $1.064 \mu \mathrm{m}$ with 750 ps pulsewidth and mode-locked frequency of $76 \mathrm{MHz}$. The laser is directly fixed on the telescope structure. The laser beam is launched behind the secondary mirror which gives smaller symmetric elongation spots on the wave front sensor. Gemini North got its first LGS light in $2005^{9}$. ESO has also developed an $8 \mathrm{~W} \mathrm{cW}$ dye laser (PARSEC) which is also launched behind the secondary mirror of VLT. The beam is propagated to the projector using a PCF optical fibre. ESO got very recently its first $\operatorname{light}^{10}$. These three LGS systems give approximately the same returned flux at $589 \mathrm{~nm}$ $\left(\sim 10^{6}\right.$ photons $\left./ \mathrm{s} / \mathrm{m}^{2}\right)$ and same LGS size (1-1.4 arcsec).

* pique@spectro.ujf-grenoble.fr; phone +33 476 514745; fax +33 476514745 


\subsection{Polychromatic Laser Guide Star}

However, the apparent direction of the LGS is independent of the tip-tilt. Therefore the tip-tilt cannot be measured. The way to overcome the tip-tilt indetermination problem of LGSs is to use a natural guide star (TTNGS). As a result, another limitation came out: the probability to find a natural star bright enough is very small in the case of visible observation ${ }^{11}$. The way to increase the sky coverage up to $100 \%$ is to use a polychromatic laser guide star (PLGS) ${ }^{12}$. The concept of the PLGS relies on the chromatic properties of the atmospheric refractive index. It consists in exciting mesospheric sodium atoms up to a level from which a radiative decay produces chromatic components spanning from a large enough spectral range. The $330 \mathrm{~nm}$ transition from the $4 \mathrm{P}_{3 / 2}$ level to the ground state $3 \mathrm{~S}_{1 / 2}$ is of special interest due to the large dispersion of the atmosphere at this wavelength. The tip-tilt angle $\theta$ can then be corrected through the measurement of the differential tip-tilt $\Delta \theta$ between two chromatic components (TTLGS for "tip-tilt laser guide star"). The relation between $\theta$ and $\Delta \theta$ is: $\theta=\left(n_{3}-1\right) / \Delta n . \Delta \theta \approx 20 . \Delta \theta$ where $n_{3}$ is the refractive index at the observation wavelength and $\Delta n$ is the differential refractive index of the two chromatic components. Depending on the chromatic components the refractive index factor is about 20. This means that the differential tip-tilt measurement must be 20 times more precise than the direct tip-tilt measurement with a natural guide star. The TTLGS must be extremely intense. This makes the difficulty of the PLGS concept which must be demonstrated on sky (ELPOA program). We propose a new way of sodium atoms excitation in order to increase by at least one order of magnitude the TTLGS intensity.

\section{TIME, SPATIAL AND SPECTRAL LASERS SODIUM INTERACTION RATE EQUATION MODEL}

\subsection{Model}

Figure $1 \mathrm{~b}$ below shows the two photon excitation scheme which has been proposed 10 years ago to produce PLGSs. A double resonant excitation with two lasers at $589 \mathrm{~nm}$ and $569 \mathrm{~nm}$ puts population to the $4 \mathrm{D}_{5 / 2}$ level of the sodium atom. This induces a radiative cascade from UV to IR. The $\mathrm{D}_{2}$ line can be used for the LGS and others chromatic components for the TTLGS. We have proposed ${ }^{13}$ another scheme with only one laser excitation at $330 \mathrm{~nm}$ which is more efficient. This possibility was rejected in paper 12 probably because of strong saturation problems. Thanks to our modeless laser development ${ }^{14}$ this solution becomes extremely interesting. Figure 1a below shows that the $4 \mathrm{P}_{3 / 2}$ level can be directly excited, from the ground state $3 \mathrm{~S}_{1 / 2}$, with a laser centered at $30272.51 \mathrm{~cm}^{-1}(\sim 330 \mathrm{~nm})$. The goal of the model was to find the laser power one need to equal the returned flux of the sodium transition at $330 \mathrm{~nm}$. We have shown that, at the mesosphere level, a laser of $1 \mathrm{~W}$ at $330 \mathrm{~nm}$ is enough to get the same returned flux at $330 \mathrm{~nm}$ as the one which is obtained with two lasers of $15 \mathrm{~W}$ each at $589 \mathrm{~nm}$ and $569 \mathrm{~nm}$.

a)

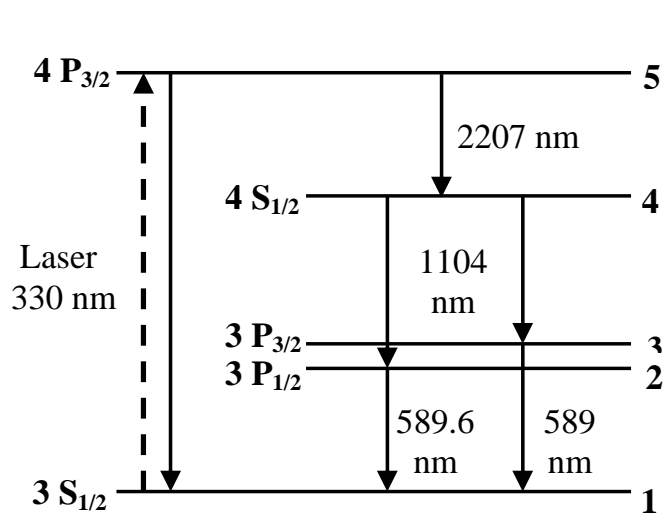

b)

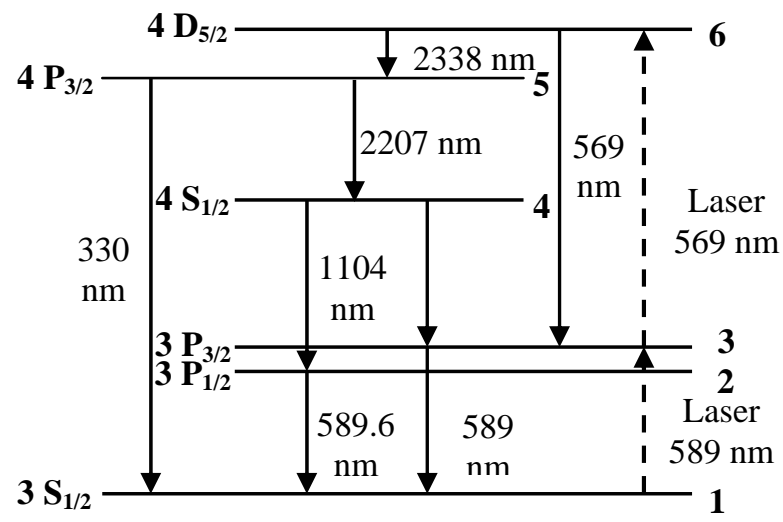

Fig. 1. Energy diagram and relaxation pathways of: a) one photon excitation of the $4 \mathrm{P}_{3 / 2}$ sodium level at $330 \mathrm{~nm}$; b) two photon excitation of the $4 \mathrm{D}_{5 / 2}$ sodium level at $589 \mathrm{~nm}+569 \mathrm{~nm}$. 
The time, spectral and spatial rate equation system that we have used is the following:

$$
\begin{aligned}
& \frac{\partial N_{1}(t, \mathbf{r}, v)}{d t}=-N_{1}(t, \mathbf{r}, v) \frac{g_{1}}{g_{5}} \int_{-\infty}^{+\infty} \sigma\left(v^{\prime}-v\right) \Phi\left(t, \mathbf{r}, v^{\prime}\right) d v^{\prime} \\
& +\left(\frac{N_{5}(t, r, v)}{\tau_{51}}+\frac{N_{2}(t, r, v)}{\tau_{21}}+\frac{N_{3}(t, r, v)}{\tau_{31}}\right) \\
& +N_{5}(t, r, v) \int_{-\infty}^{+\infty} \sigma\left(v^{\prime}-v\right) \Phi\left(t, r, v^{\prime}\right) d v^{\prime} \\
& \frac{\partial N_{2}(t, r, v)}{d t}=\frac{N_{4}(t, r, v)}{\tau_{42}}-\frac{N_{2}(t, r, v)}{\tau_{21}} \\
& \frac{\partial N_{3}(t, r, v)}{d t}=\frac{N_{4}(r, t, v)}{\tau_{43}}-\frac{N_{3}(t, r, v)}{\tau_{31}} \\
& \frac{\partial N_{4}(t, r, v)}{d t}=-\frac{N_{4}(t, r, v)}{\tau_{43}}-\frac{N_{4}(t, r, v)}{\tau_{42}}-\frac{N_{5}(t, r, v)}{\tau_{54}} \\
& \frac{\partial N_{5}(t, r, v)}{d t}=N_{1}(t, r, v) \int_{-\infty}^{+\infty} \sigma\left(v^{\prime}-v\right) \Phi\left(t, r, v^{\prime}\right) d v^{\prime} \\
& -\frac{N_{5}(t, r, v)}{\tau_{54}}-\frac{N_{5}(t, r, v)}{\tau_{51}} \\
& -N_{5}(t, r, v) \frac{g_{1}}{g_{5}} \int_{-\infty}^{+\infty} \sigma\left(v^{\prime}-v\right) \Phi\left(t, r, v^{\prime}\right) d v^{\prime} \\
& \sum_{i=1}^{5} N_{i}(t, r, v)=N_{D}(v)=N_{1}(t=0, r, v)
\end{aligned}
$$

where $t$ is the time, $r$ the radial position, $v$ the frequency, $g_{1} / g_{5}$ the degeneracy of the $3 \mathrm{~S}_{1 / 2}$ and $4 \mathrm{P}_{3 / 2}$ states, $1 / \tau_{i j}$ the rate of the transition $\mathrm{i} \rightarrow \mathrm{j}, \Phi$ the laser photon flux density, $\sigma$ the homogeneous absorption cross section, $N_{i}$ the population of the level i and $N_{D}$ the Doppler distribution population. Similar equations system was used for the 2 photon excitation scheme. Figure 2 summarize our calculation using lasers of $17 \mathrm{kHz}$ repetition rate and $50 \mathrm{~ns}$ pulse width. It is clear that modeless lasers give the best result. The actual ELPOA program with the two photon excitation scheme will produce $4 \times 10^{4}$ photons $/ \mathrm{s} / \mathrm{m}^{2}$ as the one photon scheme with $10 \mathrm{~W}$ at $330 \mathrm{~nm}$ can produce $3 \times 10^{5}$ photons $/ \mathrm{s} / \mathrm{m}^{2}$. Figure 2 shows that using single mode lasers the $330 \mathrm{~nm}$ excitation scheme is not relevant. Only modeless laser makes this solution very attractive. The slope of curve 3 can be larger for higher repetition rate and pulse width. A returned flux up to $10^{6}$ photons $/ \mathrm{s} / \mathrm{m}^{2}$ is technically attainable using robust solid state laser material with moderated mean power. This point is developed latter on. 


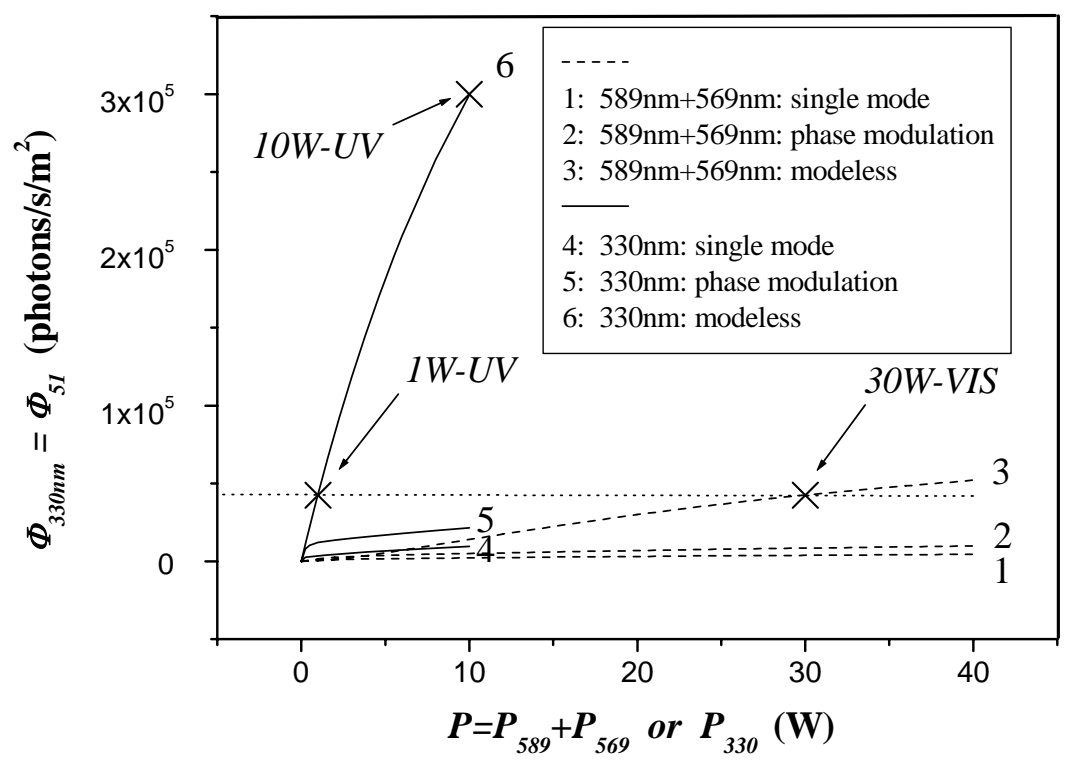

Fig. 2. Return fluorescence flux at 330nm versus average laser power for the three types of lasers: a) $1 \mathrm{MHz}$ single mode laser (curves 1 and 4), b) $1 \mathrm{MHz}$ single mode laser followed by a double phase modulation at $180 \mathrm{MHz}$ and $325 \mathrm{MHz}$ (curves 2 and 5) and c) modeless laser (curves 3 and 6). Solid curves correspond to the one photon excitation at 330nm (case 1) and dashed curves to the two photon excitation at 589nm $+569 \mathrm{~nm}$ (case 2). The cross located at 30W-VIS on curve 3 corresponds to the ELP-OA project. The cross at $1 \mathrm{~W}$-UV on curve 6 corresponds to the UV laser power at $330 \mathrm{~nm}$ that equalize the flux of photons of the ELP-OA project. The cross at $10 \mathrm{~W}-\mathrm{UV}$ on curve 6 corresponds to the flux that is close to the required flux. $10 \mathrm{~W}$ in case 1 gives 12 times more flux than $30 \mathrm{~W}$ in case 2.

\subsection{Discussion}

The main three results of this work are:

1. using modeless lasers of $2 \times 15 \mathrm{~W}^{\dagger}$ at $589 \mathrm{~nm}+569 \mathrm{~nm}$ or $1 \mathrm{~W}$ laser at $330 \mathrm{~nm}$ will produce the same returned flux at $330 \mathrm{~nm}\left(\sim 4 \times 10^{4}\right.$ photons $\left./ \mathrm{s} / \mathrm{m}^{2}\right)$.

2. for the two photon excitation scheme, the flux at $330 \mathrm{~nm}$ is about 100 times weaker than the flux at $589 \mathrm{~nm}\left(\mathrm{D}_{2}\right.$ line).

3. if one needs 10 times more flux, only $10 \mathrm{~W}$ of a laser operating at $330 \mathrm{~nm}$ will be sufficient; whereas even with two $200 \mathrm{~W}$ lasers at $589 \mathrm{~nm}+569 \mathrm{~nm}$ it will be extremely difficult to reach this gain (see slopes of curve 3 and 6 of figure 2).

Points 1 and 2 are in very good agreement with two theoretical works using density matrix methods. It has been demonstrated $^{15}$ that taking, in the two photon excitation scheme, $2 \times 25 \mathrm{~W}$ lasers which are able to cover all velocity classes of sodium atoms (equivalent to our modeless laser) and taking an atomic column density of $5 \times 10^{9} \mathrm{atoms} / \mathrm{cm}^{2}$, a returned flux of $10^{5}$ photons $/ \mathrm{s} / \mathrm{m}^{2}$ is obtained. If one correct for the values of our parameters (i.e. $2 \times 15 \mathrm{~W}$ and $4 \times 10^{9}$ atoms $/ \mathrm{cm}^{2}$ ) one get a result which is very close to our calculation (point 1). Again in the two photon excitation scheme, it has been clearly shown ${ }^{16}$ that the flux at $330 \mathrm{~nm}$ is 100 times weaker that the returned flux on the $\mathrm{D}_{2}$ line (see figure 3 of reference 16). The consequence is that, because the measured $\mathrm{D}_{2}$ flux at Keck II, Gemini and VLT/ESO is about $10^{6} \mathrm{photons} / \mathrm{s} / \mathrm{m}^{2}$ with similar laser power, the two photons excitation scheme cannot produce a flux at $330 \mathrm{~nm}$ larger than about $10^{4}$ photons $/ \mathrm{s} / \mathrm{m}^{2}$. As this flux could be largely insufficient for PLGS programs, point 3 is a very good news.

We have shown that our model is also in very good agreement with experiments on sky: PASS-1 with LLNL lasers ${ }^{17}$, PASS-2 with CEA lasers ${ }^{18}$ and PASS-2 with LSP lasers.

\footnotetext{
${ }^{\dagger}$ Laser power is given at the mesosphere level.
} 


\section{ONE PHOTON EXCITATION VERSUS TWO PHOTON EXCITATION}

Here is summarized the advantages and disadvantages of both solutions

\subsection{Disadvantages of the two photon excitation}

- Complex double high power modeless lasers system (see figure 3a below)

- Two identical lasers

- $\quad$ Time synchronization of pulses (time jitter)

- $\quad$ Spatial overlap of two beams

- $1 \mathrm{GHz}$ line width at $569 \mathrm{~nm}$ difficult

- $\quad$ Returned flux at $330 \mathrm{~nm}$ limited: no real possibility to increase the flux with reasonable laser power

- $\quad$ No solid state laser solution

\subsection{Advantages of the one photon excitation}

- $\quad$ Simple one modeless laser system (see figure 3b below)

- $\quad$ No time synchronization and spatial overlap

- $\quad 3.5 \mathrm{GHz}$ line width at $330 \mathrm{~nm}$ easy (i.e. $5 \mathrm{GHz}$ at $660 \mathrm{~nm}$ )

- $\quad 50 \%$ population of the $4 \mathrm{P}_{3 / 2}$ level by incoherent excitation

- Possibility to increase the returned flux at $330 \mathrm{~nm}$ up to $10^{6}$ photons $/ \mathrm{s} / \mathrm{m}^{2}$ with reasonable laser power

- In the later case a single $330 \mathrm{~nm}$ laser is enough to produce at the same time the TTLGS and LGS

- $\quad$ Several robust solid state laser solutions

\section{LASERS TECHNOLOGIES}

\subsection{Dye lasers}

Unfortunately no solid state lasers can generate $569 \mathrm{~nm}$. For the moment only dye lasers allow these wavelengths with high powers and high efficiency. The isotopic separation programs have demonstrated that it is possible to obtain 1000 $\mathrm{W}$ in the visible range ${ }^{19}$. In order to solve the limitation due to the saturation of sodium transitions, we have developed a dye modeless laser. A great advantage of dye lasers is their large wavelength tunability. The same modeless laser channel can generate $589 \mathrm{~nm}, 569 \mathrm{~nm}$ and $330 \mathrm{~nm}$. Figure 3a below shows the ELPOA laser channels under development. Because of the large hyperfine structure $(1.77 \mathrm{GHz})$ of the ground state of sodium atom, the $589 \mathrm{~nm}$ laser requires a line width of $3 \mathrm{GHz}$. It is attainable with a single intra cavity etalon (F). 15-20W can be obtained using two 50 W YAG pump lasers operating at $532 \mathrm{~nm}$ or CuHBr lasers ${ }^{20}$. The $569 \mathrm{~nm}$ channel is more difficult because the line width must be $1 \mathrm{GHz}$. This modeless laser line width has not yet been demonstrated. A more efficient intracavity etalon has to be developed which implies more intra cavity losses. Then, they must be compensated with higher cw pump power and more efficient intra cavity acousto-optic frequency shifter. According to our model and its validation on several sky experiments these two laser channels would produce a $330 \mathrm{~nm}$ returned flux of about $4 \times 10^{4}$ photons $/ \mathrm{s} / \mathrm{m}^{2}$ at the mesosphere. The same flux can be obtained using the much simpler $330 \mathrm{~nm}$ laser channel describes on figure $3 \mathrm{~b}$. Because of the lower wavelength, the required line width at $330 \mathrm{~nm}$ is $3.5 \mathrm{GHz}$. According to non linear effect of the second harmonic generator (SHG), the required $660 \mathrm{~nm}$ modeless line width is of $5 \mathrm{GHz}$. It is easily obtained without cw operation. The dye jet of the modeless oscillator can be directly pumped by 200 ns pulse width YAG laser of 3 W of mean power. Moreover, the 330nm laser channel amplifier requires only one $50 \mathrm{~W}$ pump YAG laser instead of four. The reliability will be much higher and for the same returned flux this solution saves at least $400 \mathrm{k} €$ of equipment. 
a)

\section{Amplifier}

CW modeless oscillator and intracavity preamplifier

\section{5-20W @589 nm, 3GHz}
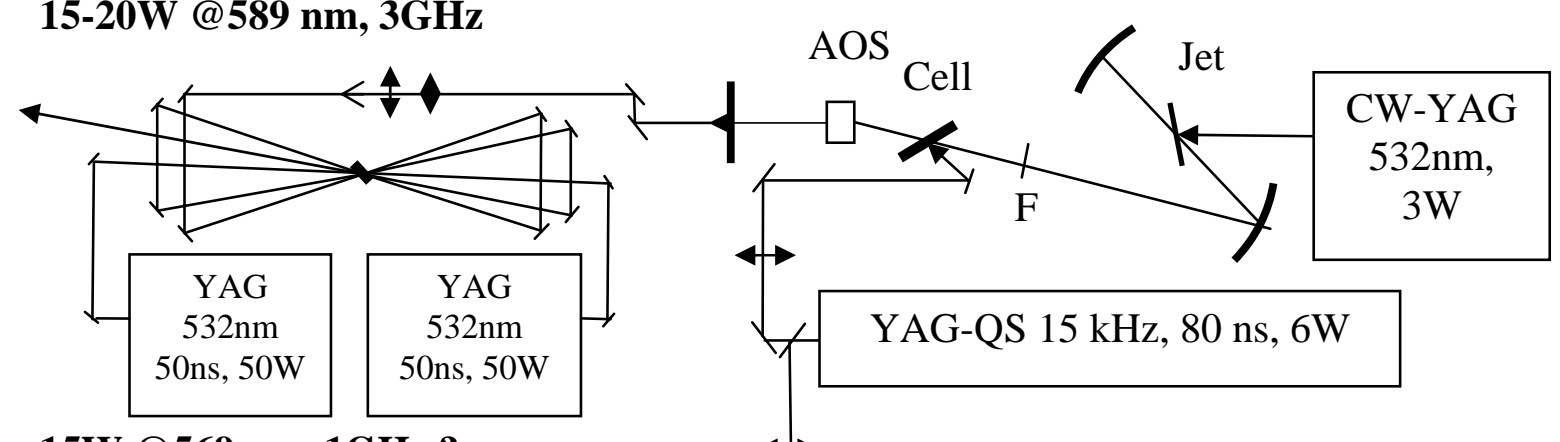

15W @569 nm, 1GHz ?
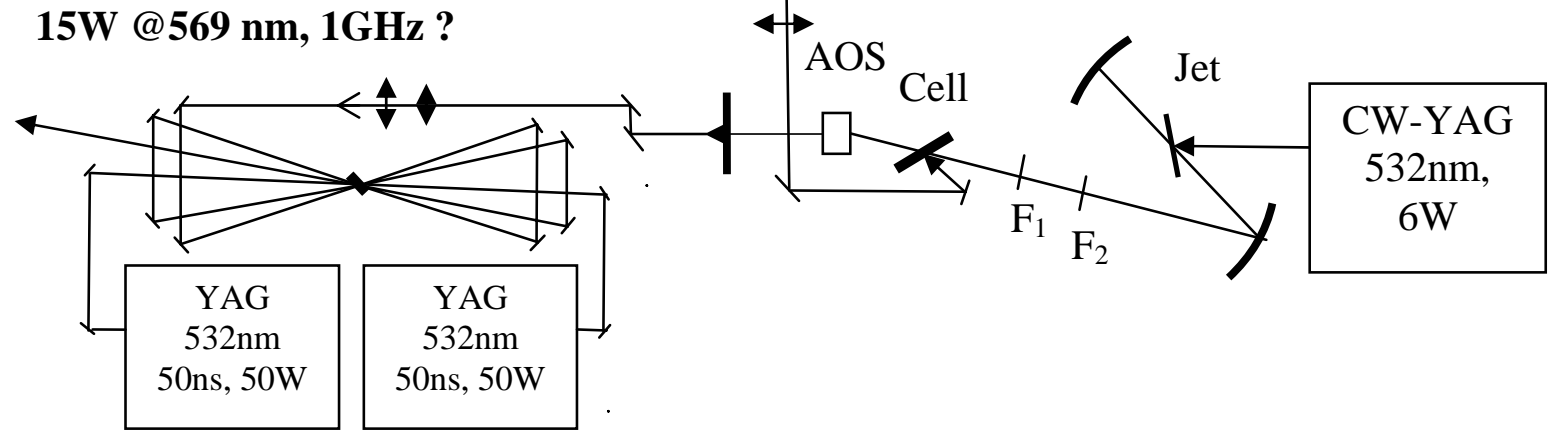

b)

\section{Amplifier}

Pulsed modeless oscillator

10W @660 nm, 5GHz

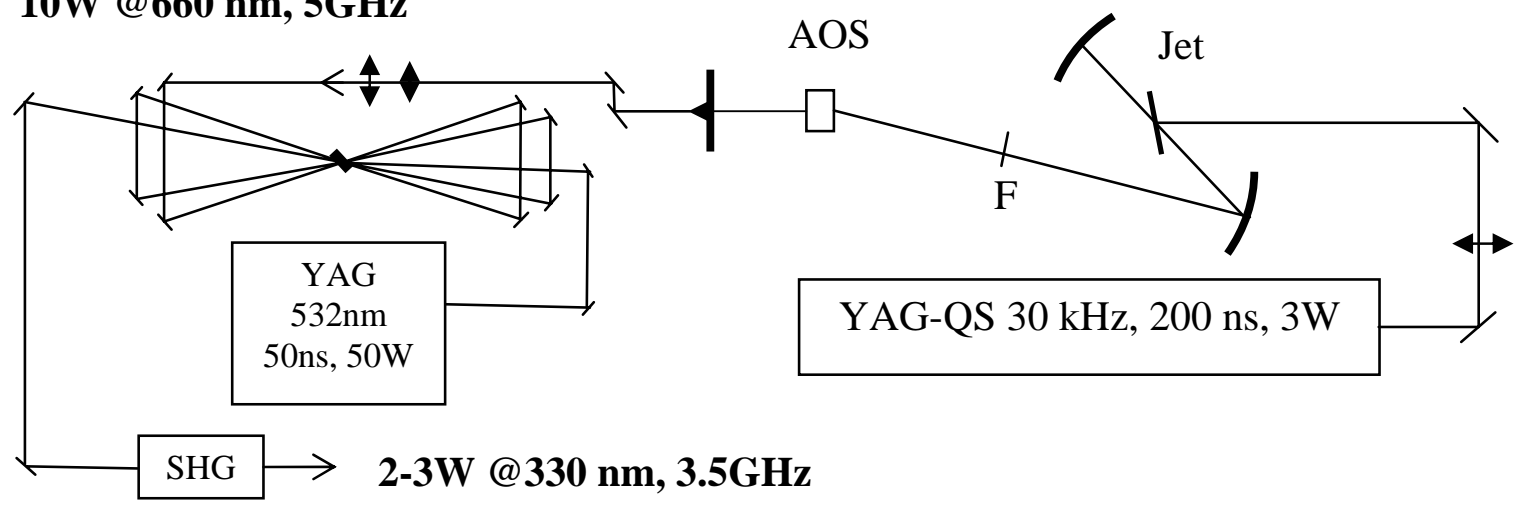

Fig 3. Two dye laser solutions for the same returned flux at $330 \mathrm{~nm}$; a) for the 2 photon excitation : 2× (15-20W) @589 nm+569 nm, $3 \mathrm{GHz}$ and $1 \mathrm{GHz}$ dye modeless laser channels; b) for the one photon excitation: 2-3W @330 nm, 3.5 $\mathrm{GHz}$ dye modeless laser channel. 


\subsection{Solid state Nd:YLF/YAG laser at $330 \mathrm{~nm}$}

Interesting coincidences exist for the production of the $330.3 \mathrm{~nm}$ line. Nd doped YAG or YLF matrix have intense laser line at $1.3 \mu \mathrm{m}$. Nd:YAG and $\mathrm{Nd}$ :YLF give a maximum gain at respectively $1319 \mathrm{~nm}$ and $1321 \mathrm{~nm}$. Using frequency quadrupling, a laser line at $330.3 \mathrm{~nm}$ can be obtained ${ }^{21}$. Figure 4 below shows the gain profile for Nd:YAG and Nd:YLF. The later is probably more favorable in terms of gain but YAG is a stronger matrix.

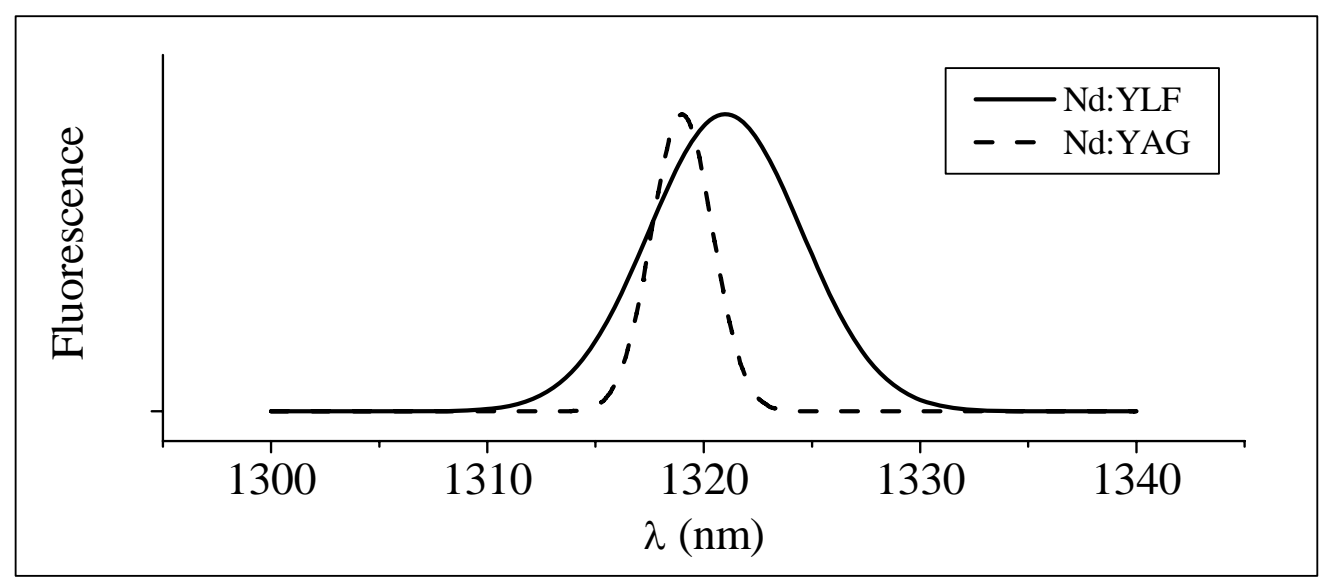

Fig. 4. Nd:YAG and Nd:YLF gain profile.

Coherent Technologies Inc has demonstrated up to $60 \mathrm{~W}$ at $1.3 \mu \mathrm{m}$ for Gemini lasers ${ }^{22}$. The corresponding laser system is made of a mode lock oscillator followed by three amplifier stages pumped by 200W diode lasers per stage. The pulse format is a CW/mode-locked with 1 ns pulses separated by 12 ns. The beam quality is very good with a $\mathrm{M}^{2}<1.4$. The spectral bandwidth is $1 \mathrm{GHz}$. This result is very encouraging for the production of high power at $330.3 \mathrm{~nm}$.

\subsection{High repetition rate modeless Ti:Sa mixed with a $532 \mathrm{~nm}$ YAG laser}

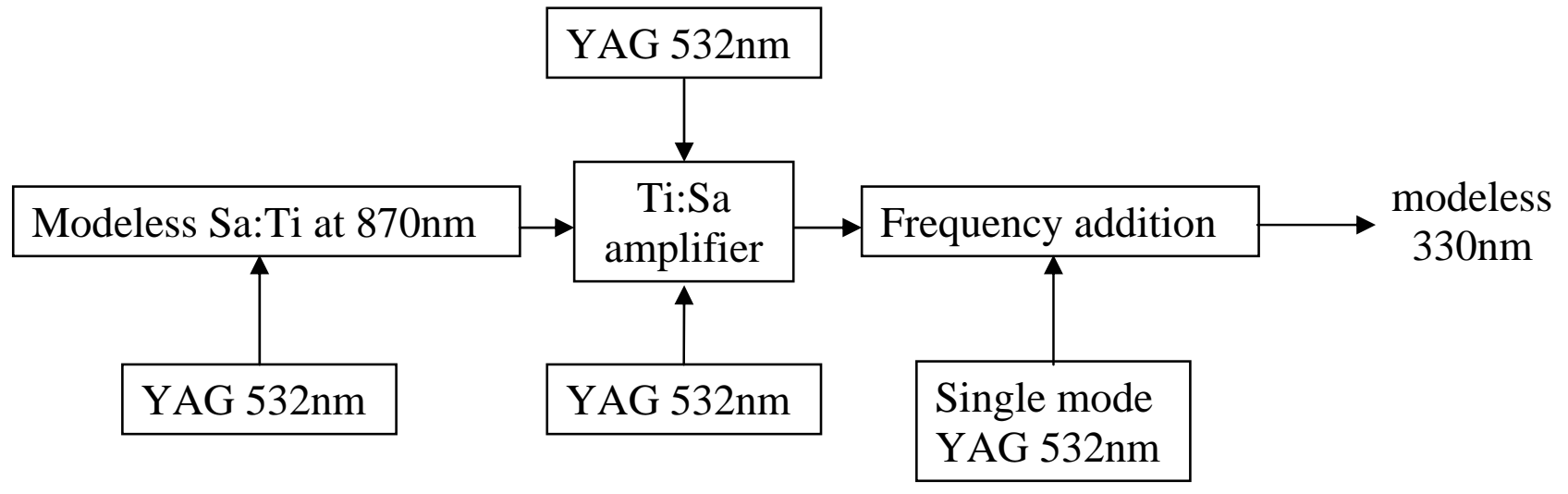

Fig. 5. Frequency addition of a 532nm Nd :YAG laser with a 870nm Sa :Ti laser for the production of $20 \mathrm{~W}$ at $330.3 \mathrm{~nm}$.

Frequency addition of a 532nm Nd:YAG laser with a $870 \mathrm{~nm}$ Sa:Ti laser is also an interesting solution for the production of the $330.3 \mathrm{~nm}$ laser line. Ultra high powers have been demonstrated for these two lasers operating in nanosecond and femtosecond regimes. Figure 5 above shows the set-up. $20 \mathrm{~W}$ at $330.3 \mathrm{~nm}$ are expected. $870 \mathrm{~nm}$ corresponds to the maximum gain of Ti:Sa laser amplifiers ${ }^{23}$. 


\subsection{Flux versus laser repetition rate and PLGS spot size}

The precision of tip-tilt correction using PLGS depends strongly on the artificial star size at the mesosphere. But, when its size decreases saturation problems start again to be a limitation. Solid state solutions we propose are interesting from this point of view as one can get higher repetition rate and pulse duration. Figure 6 below shows some examples using the model presented above.

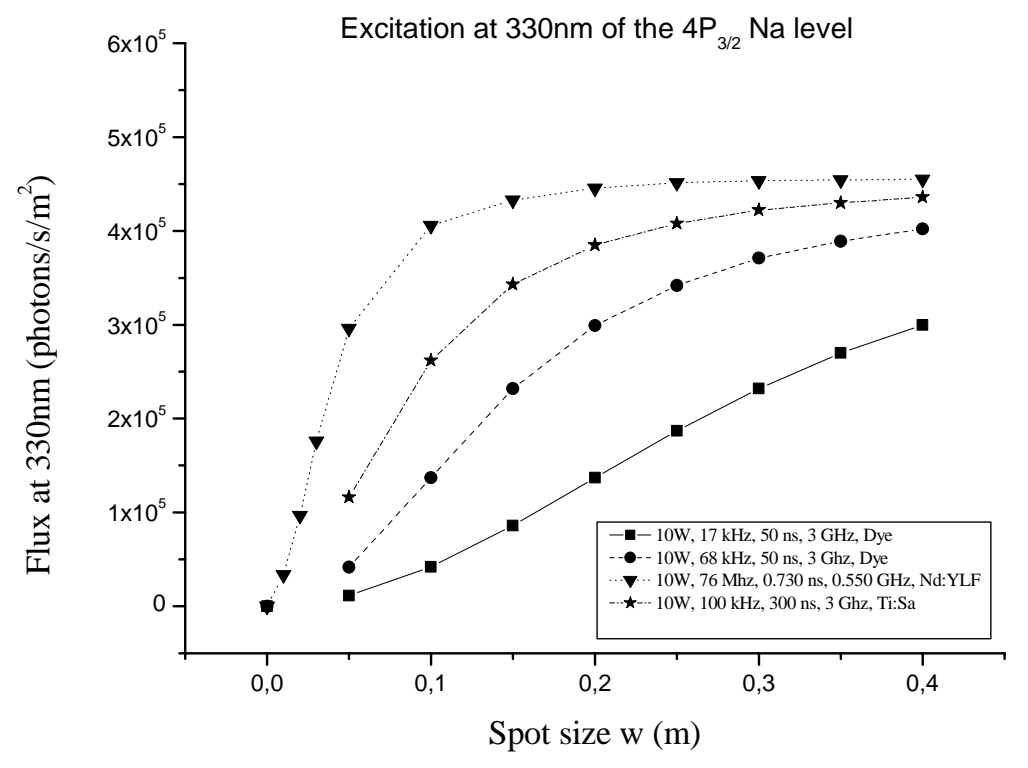

Fig. 6. Returned flux at $330 \mathrm{~nm}$ versus spot size for different laser situations.

\subsection{Rayleigh scattering}

The Rayleigh scattering of the laser beam in the first $50 \mathrm{~km}$ of its propagation to the mesosphere raises some issues about the choice of the laser solution. Rayleigh scattering is a crucial problem since it gives unwanted photon noise on the wavefront sensor. It can be limited by sending the laser beam behind the secondary mirror of the telescope. However it will be a major limitation for multiple laser beams systems (MCAO) where it is not possible to occult all beams simultaneously. A solution to cancel the noise effects of Rayleigh scattering has been tested in our group and will be the subject of a publication to come. Namely it is based on the fact that the Rayleigh scattering is $100 \%$ polarized and that the fluorescence of the sodium transitions induced by a modeless laser is almost completely depolarized, due to the hyperfine structure of the sodium atom. Thus by placing on the return path of the light an analyzer at 90 degrees from the direction of polarization of the laser beam, one can suppress completely the Rayleigh scattering and gain significant improvement of the signal to noise ratio (of course at the expense of loosing about $50 \%$ of the fluorescence signal). Recall that the possibility of canceling the effects of the Rayleigh scattering is particularly interesting for UV atmospheric propagation (UV LIDAR, $330 \mathrm{~nm}$-induced TTLGS...) since the intensity of the Rayleigh scattering evolves as $\lambda^{-4}$.

\section{ACKNOWLEDGMENTS}

This work was supported by the CNRS/SPM and CNRS/MRCT. We would like to thank T. Vacelet for helpful technical support. 


\section{REFERENCES}

1. A.R. Contos, P.L. Wizinowich, S. K. Hartman, D. Le Mignant, C.R. Neyman, P.J. Stomski and D. Summers, "Laser guide star adaptive optics at the Keck Observatory," in Adaptive Optical Sysytem Tecnologies II, Peter L.

Wizinowich, Domenico Bonaccini eds., Proceedings of SPIE, 4839, 370-380 (2003).

2. D. Bonaccini, W. Hackenberg, M. Cullum, E. Brunetto, T. Ott, M. Quattri, E. Allaert, M. Dimmler, M. Tarenghi, A. Van Kersteren, C. Di Chirico, B. Buzzoni, P. Gray, R. Tamai, and M. Tapia, "ESO VLT laser guide star facility,” in Adaptive Optics Systems and Technology II, Robert K. Tyson, Domenico Bonaccini, Michael C. Roggemann, eds., Proceeding of SPIE 4494, 276-289 (2002).

3. C. d'Orgeville, B. Bauman, J. Catone, B. Ellerbroek, D. Gavel, and R. Buchroeder, "Gemini north and south laser guide star systems requirements and preliminary designs," in Adaptive Optics Systems and Technology II, Robert K. Tyson, Domenico Bonaccini, Michael C. Roggemann, eds., Proceeding of SPIE 4494, 302-316 (2002).

4. J.Drummond, J.Telle, C.Denman, P.Hilman, and A.Tuffli, "Photometry of a sodium Laser Guide Star at Starfire Optical Range”, Pub.of the Astron. Soc. of the Pacific 116,278-289, (march 2004); J.M. Telle, P.W. Milonni, and R.Q. Fugate, “ Update on 589-nm sodium star pump laser requirements”, in Adaptive Optical Systems Technology, Peter L. Wizinowich, ed., Proceeding of SPIE 4007, 252-257 (2000).

5. S.S. Olivier, C.E. Max, H.W. Friedman, J. An, K. Avicola, B.V.Beeman, H.D. Bissinger, J.M. Brase, G.V. Erbert, D.T. Gavel, K. Kanz, B. Macintosh, K.P. Neeb and K.E. Waltjen, "First significant image improvement from a sodium-layer laser guide star adaptive optics at Lick Observatory," Proceeding of SPIE, 3126, 240 (1997).

6. P. Wizinovich, D. Le Mignant, P. Stomski, D. Scott, Acton, A. Contos, C. Neyman, ”Adaptive optics developments at Keck Observatory," in Adaptive Optical Sysytem Tecnologies II, Peter L. Wizinowich, Domenico Bonaccini eds., Proceeding of SPIE 4839, 9 (2003).

7. Peter L. Wizinowich, David Le Mignant, Antonin H. Bouchez, Randy D. Campbell, Jason.Y. Chin, Adam R. Contos, Marcos A. Van Dam, Scott K. Hartman, Erik M. Johansson, Robert E. Lafon, Hilton Levis, Paul J. Stomski, Douglas M. Summers, Curtis G. Brown, Pamela M. Danforth and Deanna M. Pennigton, "The W. M. Keck Observatory Laser Guide Star Adaptive Optics System: Overview”, preprint (2006).

8. Donald T. Gavel1 and Herbert W. Friedman, "Measurements of the Lick Observatory sodium laser guide star" Proceeding of SPIE, 3353, 260, (1998).

9. Céline d'Orgeville, Gustavo Arriagada, Matthieu Bec, Maxime Boccas, Chas Cavedoni, Simon Chan, Kenny Grace, Benjamin Irarrazaval, Eric James, Stan Karewicz, Dan O'Connor, Gabriel Perez, François Rigaut, Mike Sheehan (Gemini Observatory, Hilo, Hawaii, USA, and La Serena, Chile); Corinne Boyer (Thirty-Meter Telescope Project, Pasadena, California, USA); Brooke Gregory (Cerro-Tololo Inter-American Observatory, La Serena, Chile); Ken Groff, Allen Hankla, Camilo Lopez, Iain McKinnie, Nathan Rogers, David Sadighi, Allen Tracy (Coherent Technologies Inc., Louisville, Colorado, USA); David Le Mignant, Marcos van Dam, Robert Lafon, Peter Wizinowich (W. M. Keck Observatory, Waimea, Hawaii, USA), “Gemini North Laser Guide Star First Light”, AMOS 2005 conference proceedings, (2005) (to be published).

10. D. Bonaccini et al., "First light of the ESO laser guide star facility", Orlando SPIE Conference, paper AS08-197, (2005).

11. R. Foy, private communication.

12. R. Foy, A. Migus, F. Biraben, G. Grynberg, P.R. McClluough, M. Tallon, "The polychromatic artificial sodium star: A new concept for correcting the atmospheric tilt,” Astron. Astrophys.Suppl.Ser., 111, 569-578(1995)

13. J.P. Pique , I. C. Moldovan and V. Fesquet, " A new concept for polychromatic laser guide stars : one photon excitation of 4P3/2 level of sodium atom", J. Opt. Soc. Am. B, submitted.

14. J.P. Pique, S. Farinotti, “An efficient modeless laser for a mesospheric sodium laser guide star,” J. Opt. Soc. Am. B, 20(10), 2093-2101(2003)

15. G. Froc, E. Rosencher, B. Attal-Trétout and V. Michau, "Photon return analysis of a polychromatic laser guide star”, Optics Communications 178, 405-409 (2000).

16. Véronique Bellanger, Arnaud Courcelle and Alain Petit, "A program to compute the two-step excitation of mesospheric sodium atoms for the Polychromatic Laser Guide Star Project”, Computer Physics Communications 
162, 143-150 (2004). V. Bellanger and A. Petit, "Laser-sodium interaction for the polychromatic laser guide star project”, Proceedings of SPIE 4538, 214-221 (2002).

17. R. Foy, M. Tallon, I. Tallon-Bosc, E. Thiébaut, J. Vaillant, F.C. Foy, D. Robert, H. Friedman, F. Biraben, G. Grynberg, J.P. Gex, A. Mens, A. Migus, J.M. Weulerse and D.J. Butler, "Photometric observations of a polychromatic laser guide star," J. Opt. Soc. Am. A 17, 2236-2242 (2000).

18. M. Schöck, , J.P. Pique, A. Petit, P. Chevrou, V. Michau, G. Grynberg, A. Migus, N. Ageorges, V. Bellanger, F. Biraben, R. Deron, H. Fews, R. Foy, C. Högemann, M Laubscher, D. Müller, C. d’Orgeville, O. Peillet, M. Redfern, F. Foy, P. Segonds, R. Soden, M. Tallon, E. Thiebaut, A. Tokovinin, J. Vaillant and J.M. Weulersse, "ELP-OA: Measuring the wavefront tilt without a natural guide star", in Propagation and Imaging through the Atmosphere IV, Michael C. Roggemann, ed, Proceeding of SPIE 4125, 41-52 (2000). R. Foy, J.P. Pique, A. Petit, P. Chevrou, V. Michau, V. Prigent, G. Grynberg, A. Migus, N. Ageorges, V. Bellanger, F. Biraben, R. Deron, H. Fews, F. Foy, C. Högemann, P. Jajourel, M Laubscher, D. Müller, C. d’Orgeville, O. Peillet, M. Redfern, M. Schöck, P. Segonds, R. Soden, M. Tallon, I. Tallon-Bosc, E. Thiebaut, A. Tokovinin, J. Vaillant and J.M. Weulersse, "ELP-OA : Toward the tilt measurement from a polychromatique laser guide star”, in Adaptive Optical Systems Technology, Peter L. Wizinowich ed., Proceeding of SPIE 4007, 287 (March 2000). R. Foy, J.P. Pique, A. Petit, P. Chevrou, V. Michau, V. Prigent, G. Grynberg, A. Migus, N. Ageorges, V. Bellanger, F. Biraben, R. Deron, H. Fews, F. Foy, C.

Högemann, P. Jajourel, M Laubscher, D. Müller, C. d’Orgeville, O. Peillet, M. Redfern, M. Schöck, P. Segonds, R. Soden, M. Tallon, I. Tallon-Bosc, E. Thiebaut, A. Tokovinin, J. Vaillant and J.M. Weulersse, "Polychromatic Guide Star: Feasibility study,” in High Power Laser Ablation III, in Claude R. Phipps, ed., Proceeding of SPIE 4065, 312(2002).

19. K. Avicola, J.M. Brase, J.R. Morris, H.D. Bissinger, J.M. Duff, H.W. Friedman, D.T. Gavel, C.E. Max, S.S. Olivier, R.W. Presta, D.A. Rapp, J.T. Salmon, and K. Valtjen, “Sodium-layer laser-guide-star experimental results," J. Opt. Soc. Am. A 11, 825-831 (1994).

20. P. Coutance, G. Naylor, and J.P. Pique, « A copper HyBrID laser of high beam quality using an axial unstable cavity », IEEE J. Quantum Electron. 31(10), 1747-1752 (1995).

21. Y. Louyer, F. Balembois, M.D. Plimmer, T. Badr, P. Georges, P. Juncar, and M.E. Himbert, "Effcient cw operation of diode-pumped Nd:YLF lasers at 1312.0 and $1322.6 \mathrm{~nm}$ for a silver atom optical clock," Optics Comm., 217, 357362 (2003).

22. Allen K. Hankla, Allen J. Tracy and Lain McKinnie, 'Commercial guide star laser system Development at Lockheed Martin Coherent Technologies”, American Astronomical Society Conference, January 2006.

23. Patrick Georges, Frederick Estable, Frangois Salin, Jean Philippe Poizat, Philippe Grangier, and Alain Brun, "Highefficiency multipass Ti:sapphire amplifiers for a continuous-wave single-mode laser”, Optics Letters 16, 144-146 (1991). 